\title{
Mifepristone Has Limited Activity to Enhance the In Vivo Efficacy of Docetaxel and Enzalutamide Against Bone Metastatic and Castration-Resistant Prostate Cancer
}

\author{
YANG YANG ${ }^{1,2^{*}}, \mathrm{XIN} \mathrm{LI}^{2 *}, \mathrm{KENZA} \mathrm{MAMOUNI}^{2}, \mathrm{OMER} \mathrm{KUCUK}^{3}$ and DAQING WU ${ }^{2,4}$ \\ ${ }^{1}$ Department of Otorhinolaryngology, Union Hospital, Tongji Medical College, \\ Huazhong University of Science and Technology, Wuhan, P.R. China; \\ ${ }^{2}$ Georgia Cancer Center and Department of Biochemistry and Molecular Biology, \\ Medical College of Georgia, Augusta University, Augusta, GA, U.S.A.; \\ ${ }^{3}$ Department of Hematology and Medical Oncology, Winship Cancer Institute, \\ Emory University School of Medicine, Atlanta, GA, U.S.A.; \\ ${ }^{4}$ MetCure Therapeutics LLC, Atlanta, GA, U.S.A.
}

\begin{abstract}
Background: Mifepristone has gained great interest in its potential as a novel agent against human cancers, including prostate cancer (PCa). However, recent clinical trials using mifepristone in PCa and other cancers have been disappointing. We evaluated the in vitro and in vivo activities of mifepristone, in combination with docetaxel and enzalutamide, against bone metastatic castration-resistant PCa. Materials and Methods: The effects of mifepristone, alone or in combination with docetaxel or enzalutamide, on $\mathrm{PCa}$ cell viability, in vitro, were determined by the colorimetric assay. Intratibial model of C4-2-Luc tumors in athymic nude mice was used to evaluate the in vivo efficacy of mifepristone alone or in combination with docetaxel or enzalutamide. Tumor growth in mouse bone was assessed by serum prostate-specific antigen (PSA) levels and radiography. Results: Although mifepristone exhibits a certain degree of
\end{abstract}

\footnotetext{
Abbreviations: ANOVA: Analysis of variance; AR: androgen receptor; CI: combination index; CYP17A1: steroid $17 \alpha$ hydroxylase; CRPC: castration-resistant prostate cancer; DHT: dihydrotestosterone; GR: glucocorticoid receptor; $\mathrm{IC}_{50}$ : half maximal inhibitory concentration; IP injection: intraperitoneal injection; PCa: prostate cancer; PSA: prostate-specific antigen.

*These Authors contributed equally to this study.

Correspondence to: Dr. Daqing Wu, Department of Biochemistry and Molecular Biology, Medical College of Georgia and Georgia Cancer Center, Augusta University, Augusta, GA, U.S.A. Tel: +1 7067234137,e-mail: dwu@augusta.edu
}

Key Words: Mifepristone, castration-resistant prostate cancer, bone metastasis, docetaxel, enzalutamide. synergism with docetaxel or enzalutamide in cell culture, statistical analyses showed that combination regimens fail to demonstrate effectiveness in suppressing the skeletal growth of PCa and enhancing the in vivo efficacy of docetaxel or enzalutamide in athymic nude mice $(p>0.05)$. Conclusion: These results provide the first pre-clinical evidence suggesting that mifepristone may not effectively inhibit bone metastatic $P C a$, either as a single agent or combined with standard chemotherapy and androgen-deprivation therapy. This report may raise concerns over the clinical use of mifepristone in the management of advanced PCa.

Bone is the most common site for metastasis in prostate cancer (PCa). Autopsy findings show development of skeletal metastasis in more than $85 \%$ of PCa cases. The quality of life of patients can be significantly compromised by skeletal complications (1-3). Recent years have seen an expansion of treatment options for PCa bone metastasis, including chemotherapy (docetaxel and cabazitaxel), androgen-deprivation therapy (ADT; enzalutamide and abiraterone), immunotherapy (Sipuleucel-T) and radium-223 dichloride. Unfortunately, these new therapies only modestly prolong overall survival by $2-5$ months, and patients generally relapse and develop extremely resistant tumors within 1 year (4-6). Clearly, it is imperative to develop novel strategies to overcome therapeutic resistance and improve clinical outcomes in PCa patients (7).

Numerous trials are in progress to identify optimal treatment combinations among various standard therapies, as well as combinations with other biological agents in order to treat metastatic castration-resistant PCa (CRPC). Recently, mifepristone (RU486) has gained great interest regarding its potential use as an anti-cancer agent (8-11). As an 
abortifacient, mifepristone was approved in France and China in 1988 and in the United States in 2000 (12). Mifepristone is safe and effective when used to terminate a pregnancy and has been on the World Health Organization Model List of Essential Medicines. A number of pre-clinical studies demonstrated that mifepristone has significant growth inhibition and antitumor effects on various human cancer cells, including PCa $(8,13)$. At least ten clinical trials have been conducted, and more are being performed to evaluate the efficacy of mifepristone in treating several solid tumors (14-17). Some patients in these trials had complete or partial response (for example, in refractory ovarian cancer), whereas other patients had no response (8). In a non-randomized phase II study, mifepristone failed to demonstrate any benefits in producing a prostate-specific antigen (PSA) response in patients with CRPC (18). Surprisingly, mifepristone treatment markedly increased adrenal androgens, testosterone, and dihydrotestosterone (DHT). These results indicated that as a single agent, mifepristone has limited clinical activity against CRPC. A reasonable speculation is that mifepristone may demonstrate better efficacy when combined with standard therapies. Indeed, a randomized, open-label phase I/II study is being conducted to test whether the combination of mifepristone and enzalutamide can extend PSA progressionfree survival in CRPC patients (NCT02012296).

Using an intratibial model of CRPC, we evaluated the in vivo efficacy of the combination of mifepristone with two major treatments for bone metastatic CRPC, docetaxel and enzalutamide. Herein we report that both combinations fail to effectively suppress the skeletal growth of CRPC in mouse models.

\section{Materials and Methods}

Cell culture and reagents. Human PCa cell lines C4-2, C4-2-Luc, and $\mathrm{C} 4-2 \mathrm{~B}$ were provided by Dr. Leland WK Chung (Cedars Sinai Medical Center, Los Angeles, CA, USA), and CWR-22Rv1 cells were provided by Dr. Jindan Yu (Northwestern University, Chicago, IL, USA). Cells were routinely maintained at $37^{\circ} \mathrm{C}, 5 \% \mathrm{CO}_{2}$ and 95\% humidity in T-medium (Invitrogen, Carlsbad, CA, USA) with 5\% fetal bovine serum (FBS; Atlanta Biologicals, Atlanta, GA, USA) or RPMI1640 medium (Corning, Corning, NY, USA) supplemented with $10 \%$ FBS. A final concentration of $400 \mu \mathrm{g} / \mathrm{ml}$ of G418 (Invitrogen, Carlsbad, CA, USA) was added to maintain luciferase expression in C4-2-Luc cells. Mifepristone was obtained from Sigma Aldrich (St. Louis, MO, USA). Docetaxel was obtained from LC Laboratories (Woburn, MA, USA) and enzalutamide (MDV3100) from Selleckchem (Houston, TX, USA).

Cell proliferation assay. Cell proliferation was measured using the CellTiter 96 AQueous Non-Radioactive Cell Proliferation (MTS) Assay kit (Promega, Madison, WI, USA) or Cell Counting Kit-8 (CCK-8; Dojindo Laboratories, Kumamoto, Japan), according to the manufacturer's instructions. For the cell viability assay, $4 \times 10^{3}$ cells per well were seeded in 96-well plates overnight and treated with

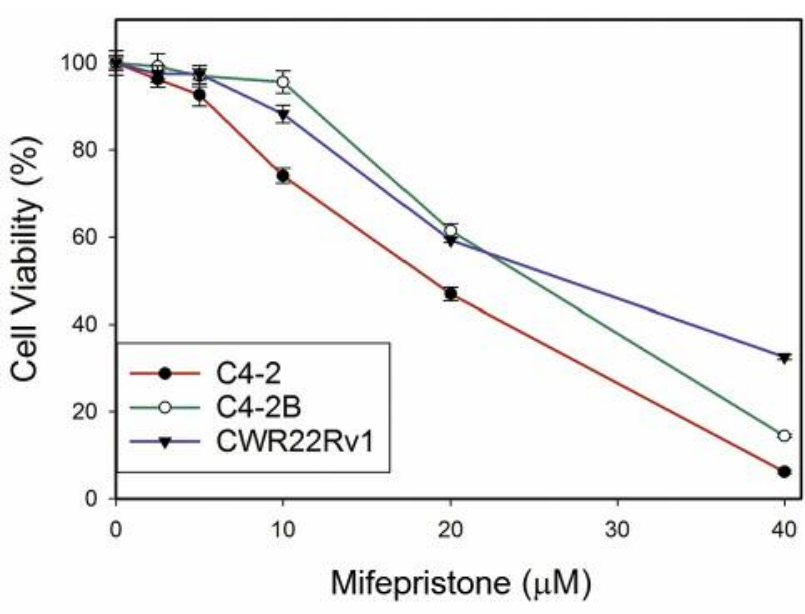

Figure 1. In vitro cytotoxicity of mifepristone in CRPC cells. AR-positive $C 4-2, C 4-2 B$, and CWR-22Rv1 cells were cultured in varying concentrations of mifepristone for $72 \mathrm{~h}$. Cell viability was determined by MTS or CCK-8 assays. AR, Androgen receptor; CRPC, castrationresistant prostate cancer; MTS, 3-(4,5-dimethylthiazol-2-yl)-5-(3carboxymethoxyphenyl)-2-(4-sulfophenyl)-2H-tetrazolium); $C C K-8$, cell counting kit-8 (Dojindo).

mifepristone, docetaxel, enzalutamide, combination of mifepristone and docetaxel, combination of mifepristone and enzalutamide, or vehicle control at the indicated concentrations for $72 \mathrm{~h}$. A microplate reader (Bio-Rad Laboratories, Hercules, CA, USA) was used to determine cell viability, which was expressed as relative survival compared to controls recorded as $100 \%$. Combination index (CI) between mifepristone and docetaxel or enzalutamide was determined using the CompuSyn software (ComboSyn, Inc).

In vivo treatment with the combination of mifepristone and docetaxel in the intratibial model of C4-2-Luc cells. All animal procedures were approved by the Augusta University Institutional Animal Care and Use Committee (IACUC). Athymic male nude mice (Hsd: athymic nude-nu; 5-week-old) were purchased from Harlan Laboratories (Indianapolis, IN, USA). For each mouse, a total of $2.0 \times 10^{6} \mathrm{C} 4$-2-Luc cells were inoculated into the bilateral tibia as we described previously (19). Blood specimens were obtained from the facial veins every week for serum PSA determination using an ELISA kit from United Biotech, Inc (Mountain View, CA, USA). With the confirmation of positive PSA levels, a total of 35 tumor-bearing mice were randomly divided into 6 groups, and received the following injection via the intraperitoneal (IP) route for the indicated time: vehicle control group ( $n=5): 100 \%$ DMSO, 3 times per week; docetaxel group $(\mathrm{n}=5): 5 \mathrm{mg} / \mathrm{kg}$ body weight, once per week; mifepristone: $30 \mathrm{mg} / \mathrm{kg}(\mathrm{n}=5)$ or $60 \mathrm{mg} / \mathrm{kg}$ $(\mathrm{n}=6), 3$ times per week; or combination group: $5 \mathrm{mg} / \mathrm{kg}$ of docetaxel, once per week, and $30 \mathrm{mg} / \mathrm{kg}(\mathrm{n}=7)$ or $60 \mathrm{mg} / \mathrm{kg}(\mathrm{n}=7)$ of mifepristone, 3 times per week. Mice were weighed twice a week, and tumor growth in bilateral tibia was followed by serum PSA measurements. X-ray analyses were performed at a time close to endpoint with Faxitron MX20 digital radiography system (Faxitron Bioptics, LLC; Tucson, AZ, USA). 
A

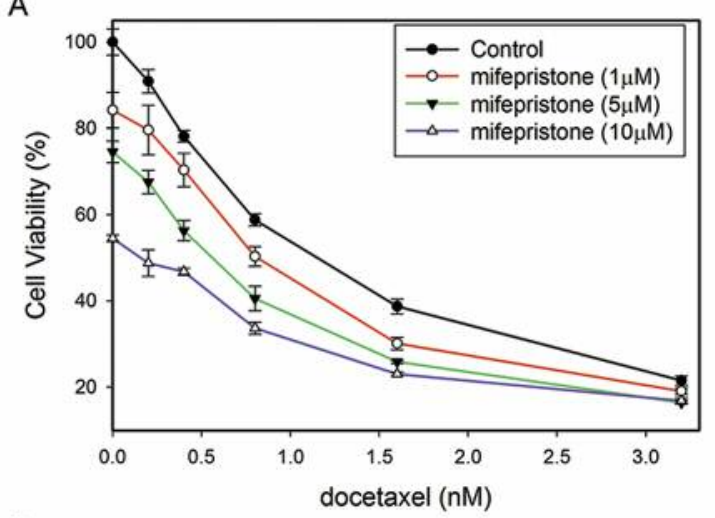

B

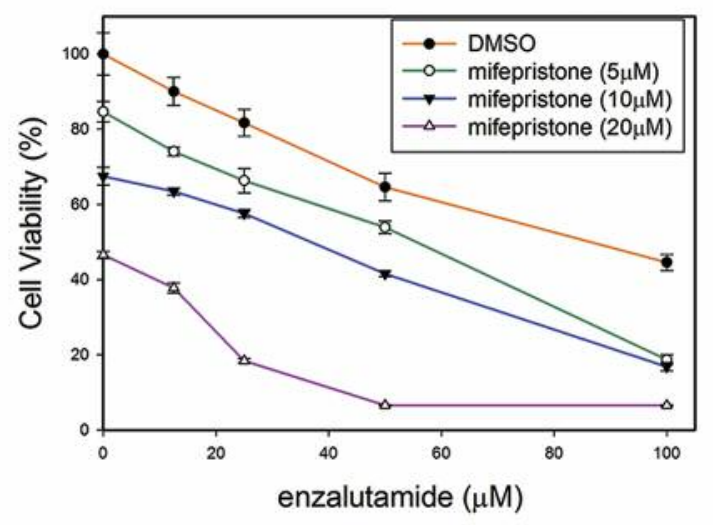

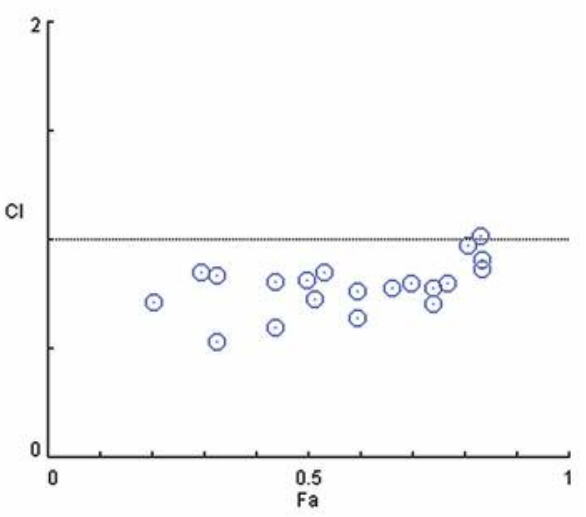

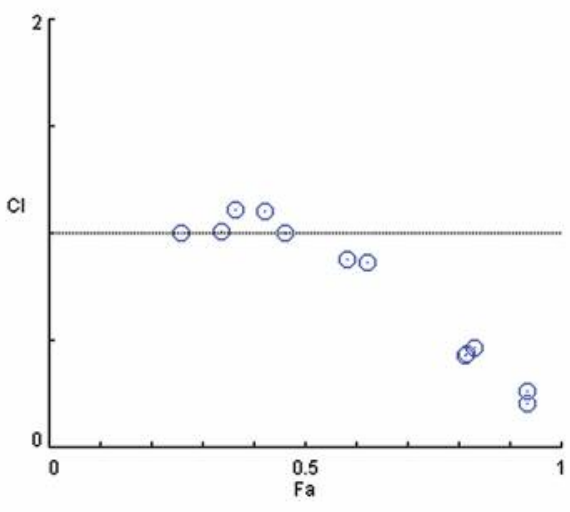

Figure 2. In vitro effects of the combinations of mifepristone with docetaxel or enzalutamide in CRPC cells. C4-2 cells were treated with varying concentrations of mifepristone, in combination with docetaxel (A) or enzalutamide (B), for $72 \mathrm{~h}$. CI was calculated using the CompuSyn software that provides quantitative definition of synergism $(C I<1)$, additive effect $(C I=1)$, and antagonism $(C I>1)$ between two or more drugs. CRPC, Castration-resistant prostate cancer; CI, Combination index.

In vivo treatment with the combination of mifepristone and enzalutamide in the intratibial model of C4-2-Luc cells. C4-2-Luc tumor inoculation was performed as described above. A total of 20 tumor-bearing mice were randomly divided into four groups and received the following injection via the IP route for the indicated time: vehicle control group ( $n=5)$ : 100\% DMSO, 3 times per week; enzalutamide group $(\mathrm{n}=5): 30 \mathrm{mg} / \mathrm{kg}$ body weight, 3 times per week; mifepristone $(\mathrm{n}=5): 30 \mathrm{mg} / \mathrm{kg}, 3$ times per week; or combination group ( $\mathrm{n}=5): 30 \mathrm{mg} / \mathrm{kg}$ of enzalutamide and $30 \mathrm{mg} / \mathrm{kg}$ of mifepristone, 3 times per week. Mice were weighed twice a week, and tumor growth in bilateral tibia was followed by weekly serum PSA assays. X-ray radiography was performed at a time close to endpoint.

Statistical analysis. A two-way analysis of variance (ANOVA) model was used to assess the longitudinal effect of treatment between each pair of groups during the whole study period. The significance levels were set at 0.05 for all tests. The SigmaPlot 13.0 package (Systat Software, Inc., San Jose, CA) was used for data management and analysis.

\section{Results}

In vitro cytotoxicity of mifepristone in CRPC cells. Previous studies have demonstrated that mifepristone inhibits the growth of human cancer cells originating from various sites, including brain, breast, prostate, ovary and bone (8). We evaluated the in vitro cytotoxicity of mifepristone in a panel of androgen receptor (AR)-positive CRPC cell lines, which closely mimic the aggressive phenotypes of clinical CRPC. As shown in Figure 1, a 72-h treatment with mifepristone significantly inhibited the viability of these cells $(p<0.05)$, with the $50 \%$ inhibitory concentration $\left(\mathrm{IC}_{50}\right)$ of $19.23 \mu \mathrm{M}$, $23.96 \mu \mathrm{M}$ and $26.73 \mu \mathrm{M}$ in C4-2, C4-2B and CWR-22Rv1 cells, respectively. These data indicate that mifepristone exhibits modest cytotoxicity in CRPC cells, in vitro.

In vitro cytotoxicity of the combination of mifepristone and docetaxel or enzalutamide in CRPC cells. We examined the 
A

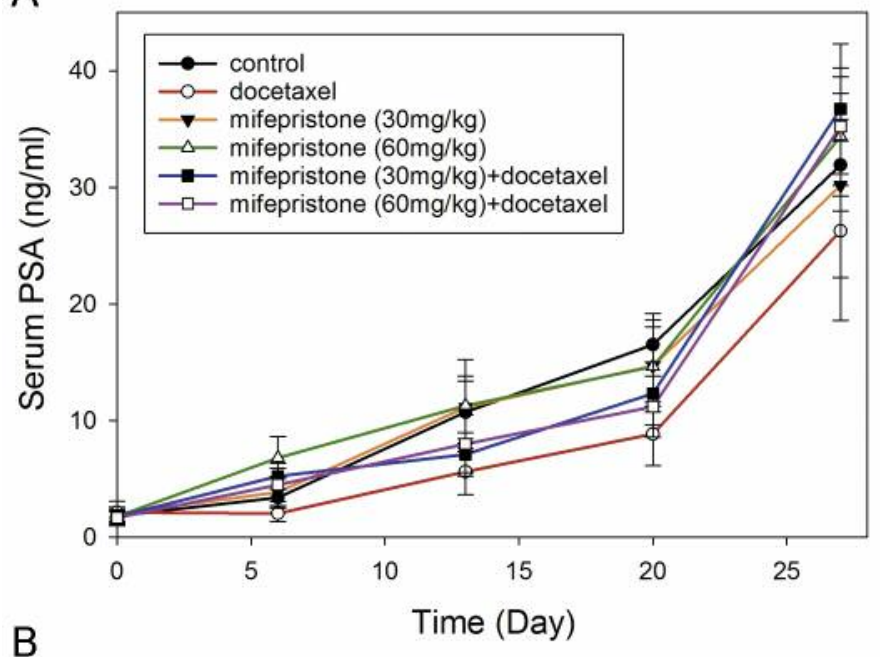

Pairwise comparison (2-Way ANOVA)
\begin{tabular}{|l|l|}
\hline Treatment & $p$-value \\
\hline Control vs Docetaxel & 0.057 \\
Control vs Mifepristone $(30 \mathrm{mg} / \mathrm{kg})$ & 0.796 \\
Control vs Mifepristone 60mg/kg & 0.671 \\
Control vs Combination $(30 \mathrm{mg} / \mathrm{kg})$ & 0.891 \\
Control vs Combination $(60 \mathrm{mg} / \mathrm{kg})$ & 0.605 \\
Docetaxel vs Mifepristone $(30 \mathrm{mg} / \mathrm{kg})$ & 0.187 \\
Docetaxel vs Mifepristone $(60 \mathrm{mg} / \mathrm{kg})$ & 0.039 \\
Docetaxel vs Combination $(30 \mathrm{mg} / \mathrm{kg})$ & 0.077 \\
Docetaxel vs Combination (60mg $/ \mathrm{kg})$ & 0.116 \\
Mifepristone $(30 \mathrm{mg} / \mathrm{kg})$ vs Mifepristone $(60 \mathrm{mg} / \mathrm{kg})$ & 0.375 \\
Mifepristone (30mg/kg) vs Combination $(30 \mathrm{mg} / \mathrm{kg})$ & 0.906 \\
Mifepristone $(60 \mathrm{mg} / \mathrm{kg})$ vs Combination $(60 \mathrm{mg} / \mathrm{kg})$ & 0.375 \\
Combination $(30 \mathrm{mg} / \mathrm{kg})$ vs Combination $(60 \mathrm{mg} / \mathrm{kg})$ & 0.755 \\
\hline
\end{tabular}

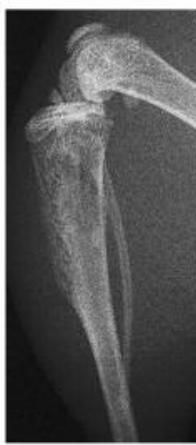

control

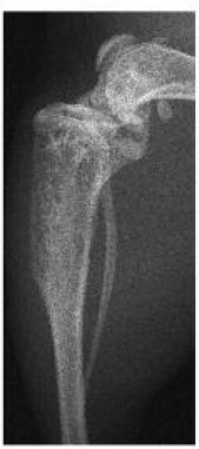

docetaxel

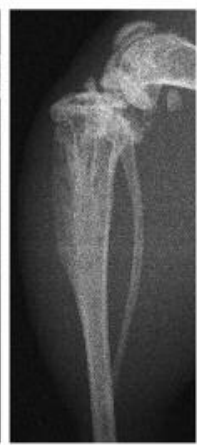

$30 \mathrm{mg} / \mathrm{kg}$

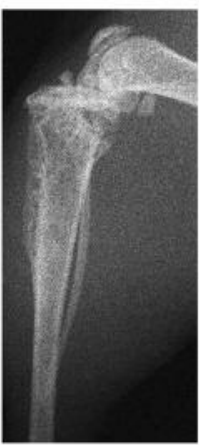

$60 \mathrm{mg} / \mathrm{kg}$

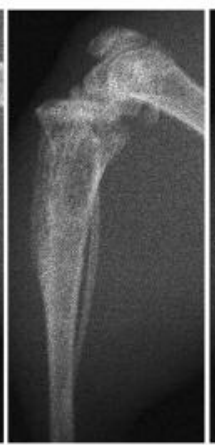

$30 \mathrm{mg} / \mathrm{kg}$

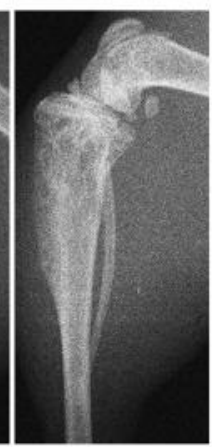

$60 \mathrm{mg} / \mathrm{kg}$

mifepristone

mifepristine + docetaxel

Figure 3. In vivo effects of mifepristone and its combination with docetaxel in C4-2-Luc intratibial model. (A) Left panel: Mifepristone alone or combined with docetaxel does not significantly reduce serum PSA levels in athymic nude mice bearing C4-2-Luc tumors; Right panel: statistical analysis on the in vivo effect of mifepristone and its combination with docetaxel. (B) X-ray radiography of C4-2-Luc-bearing tibias receiving drug treatments as indicated. PSA, Prostate-specific antigen.

combined effects of mifepristone and docetaxel, a first-line chemotherapeutic drug for CRPC, in C4-2 cells. As shown in Figure 2A, the addition of mifepristone increased the in vitro cytotoxicity of docetaxel. Quantitative analysis of doseeffect relationships using the CompuSyn software indicated there is weak to modest synergism between the two drugs, with the combination index (CI) ranging from 0.53 to 1.02 . The best synergism occured when mifepristone was used at $2.0 \mu \mathrm{M}$ and docetaxel at $0.2 \mu \mathrm{M}$.

We further tested the combined effects of mifepristone with enzalutamide, a new-generation AR antagonist. Interestingly, synergism was only observed when both mifepristone and enzalutamide were present at relatively high doses. The lowest CI occurs when mifepristone is used at $20 \mu \mathrm{M}$ and enzalutamide is used at $50 \mu \mathrm{M}$. At other doses, the combined effects of mifepristone and enzalutamide are mostly additive between the two drugs.

In vivo efficacy of combined treatment with mifepristone and docetaxel against the skeletal growth of C4-2 tumors, in vivo. We examined the in vivo efficacy of mifepristone against the skeletal growth of CRPC in an intratibial model of C4-2 cells. After the confirmation of successful tumor inoculation, athymic nude mice were treated with vehicle control, docetaxel, mifepristone or the combination of mifepristone and docetaxel. Based on our previous observations, docetaxel was administered at $5 \mathrm{mg} / \mathrm{kg}$ body weight, once per week, via IP route. Mifepristone was administered at 2 escalating doses, i.e., 30 and $60 \mathrm{mg} / \mathrm{kg}$ body weight, 3 times per week, IP. Following 4 weeks of treatment, the average PSA level in each group at the endpoint 
A

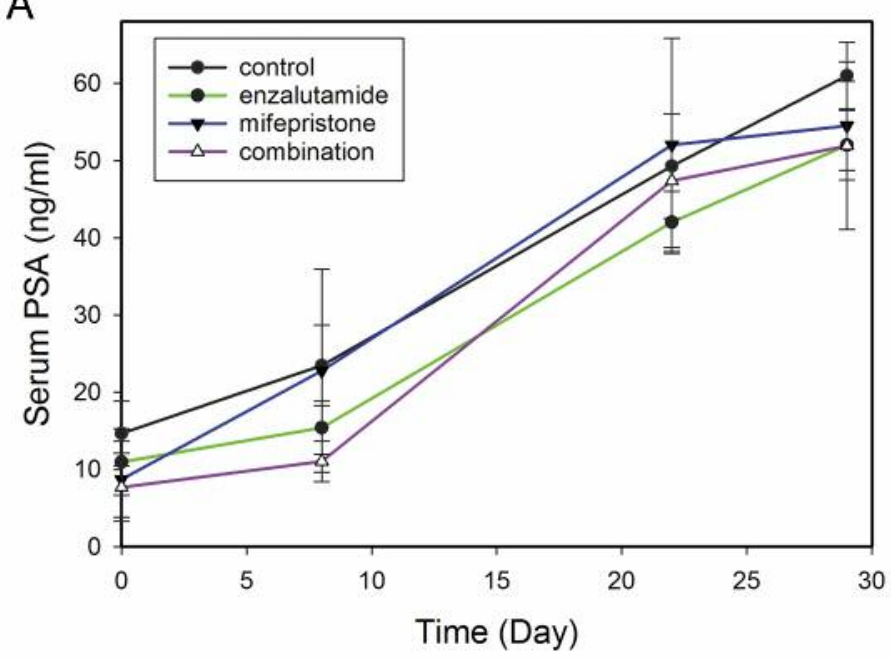

B
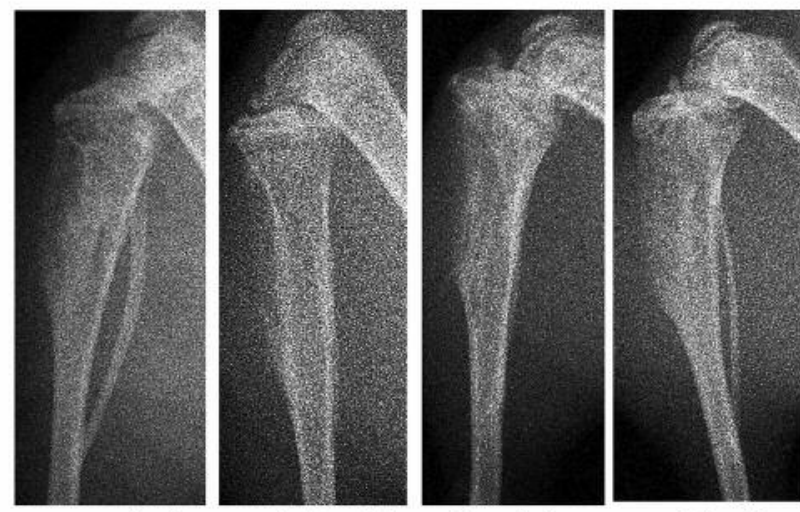

control

enzalutamide mifepristone combination

\begin{tabular}{|c|c|}
\hline \multicolumn{2}{|c|}{ Pairwise comparison (2-Way ANOVA) } \\
\hline Treatment & $p$-value \\
\hline Control ys Enzalutamide & 0.043 \\
\hline Control vs Mifepristone & 0.644 \\
\hline Control vs Combination & 0.104 \\
\hline Enzalutamide vs Combination & 0.891 \\
\hline Mifepristone vs Combination & 0.424 \\
\hline Enzalutamide vs Mifepristone & 0.410 \\
\hline
\end{tabular}

Figure 4. In vivo effects of mifepristone and its combination with enzalutamide in C4-2-Luc intratibial model. (A) Left panel: Mifepristone alone or combined with enzalutamide does not significantly reduce serum PSA levels in athymic nude mice bearing C4-2-Luc tumors; Right panel: statistical analysis on the in vivo effect of mifepristone and its combination with enzalutamide. (B) X-ray radiography of C4-2-Luc-bearing tibias receiving drug treatments as indicated. PSA, Prostate-specific antigen.

was $31.92 \pm 3.92 \mathrm{ng} / \mathrm{ml}$ (control), $26.28 \pm 7.69 \mathrm{ng} / \mathrm{ml}$ (docetaxel), $30.17 \pm 7.90 \mathrm{ng} / \mathrm{ml}$ (mifepristone, $30 \mathrm{mg} / \mathrm{kg}$ ), 34.38 $\pm 5.09 \mathrm{ng} / \mathrm{ml}$ (mifepristone, $60 \mathrm{mg} / \mathrm{kg}$ ), 36.74 $\pm 5.57 \mathrm{ng} / \mathrm{ml}$ (mifepristone, 30 $\mathrm{mg} / \mathrm{kg}$, and docetaxel), and 35.21 $\pm 5.04 \mathrm{ng} / \mathrm{ml}$ (mifepristone, 60 $\mathrm{mg} / \mathrm{kg}$ and docetaxel) (Figure 3A). Statistical analysis using a two-way ANOVA model found no significant difference in the longitudinal PSA values between any two treatment groups $(p>0.05)$, except that between the docetaxel and mifepristone group $(p=0.039)$. X-ray radiography showed that $\mathrm{C} 4-2$ tumorbearing bone treated with either mifepristone, docetaxel or the combination regimen displayed similar skeletal architectures with multiple osteoblastic and osteolytic lesions, compared with the control group (Figure 3B). These results indicated that mifepristone has limited or no effects in suppressing C4-2 tumors in mouse bones and in enhancing docetaxel efficacy.
In vivo efficacy of the combined treatment with mifepristone and enzalutamide against the skeletal growth of C4-2 tumors. We also tested the in vivo efficacy of mifepristone and enzalutamide in the intratibial model of $\mathrm{C} 4-2$ cells. A single dose (30 mg/kg body weight) of mifepristone was used in this experiment. At this dose, mifepristone appears to exhibit similar (or better, although statistically not significant) effects on C4-2 tumor growth as the dose of $60 \mathrm{mg} / \mathrm{kg}$. Enzalutamide was administered at $30 \mathrm{mg} / \mathrm{kg}$ body weight, 3 times per week, via the IP route. As shown in Figure $4 \mathrm{~A}$, the average PSA level in each group at the endpoint was $61.01 \pm 4.31 \mathrm{ng} / \mathrm{ml}$ (control), $52.02 \pm 4.53 \mathrm{ng} / \mathrm{ml}$ (enzalutamide), $54.53 \pm 5.78 \mathrm{ng} / \mathrm{ml}$ (mifepristone), and $51.95 \pm 10.86 \mathrm{ng} / \mathrm{ml}$ (combination). Statistical analysis showed that there was no significant difference in the 
longitudinal PSA values between any two treatment groups $(p>0.05)$, except that between the control and enzalutamide groups $(p=0.043)$. X-ray radiography showed that, compared with the control group, C4-2 tumor-bearing bone treated with either mifepristone, enzalutamide or the combination displayed similar skeletal architectures with multiple osteoblastic and osteolytic lesions (Figure 4B). Similarly to mifepristone and docetaxel results, mifepristone had limited or no effect in suppressing C4-2 tumors in mouse bones and in enhancing the in vivo efficacy of enzalutamide.

\section{Discussion}

A reversible and potent glucocorticoid receptor (GR) antagonist, mifepristone has gained considerable attention for its potential as an antineoplastic agent, particularly in hormone-associated cancers. Most evidence came from preclinical studies that showed that mifepristone can induce growth arrest, apoptotic lethality, and the reversal of multidrug resistance in human cancer cells from various origins (8). At the molecular level, mifepristone can affect multiple genes involved in regulation of the cell cycle (such as cyclin-dependent kinase $2 / \mathrm{cdk} 2$ ), apoptosis (such as caspase-3, B-cell lymphoma 2/Bcl-2, B-cell lymphoma-extra large/Bcl-XL, transforming growth factor $\beta 1$ ), and acquired therapeutic resistance (p-glycoprotein). In triple-negative breast cancer cells, mifepristone alone has no significant effect on cell viability, but markedly increases the effects of dexamethasone/paclitaxel treatment, presumably via the inhibition of glucocorticoid-inducible protein kinase-1 and mitogen-activated protein kinase (20). Mifepristone may also specifically inhibit the triple-negative breast cancer stem cell population by targeting Krüppel-like factor 5 (21).

The inhibitory effect of mifepristone on PCa cells seem to be independent of AR status, since the drug exhibits similar activity against the proliferation of both AR-positive PCa cells (such as LNCaP, C4, C4-2, CWR22Rv1) and ARnegative cells (such as PC-3, DU-145) (13, 22-25). Subcutaneous injection of mifepristone at a dose of 50 $\mathrm{mg} / \mathrm{kg} /$ day for 28 days has been shown to inhibit tumor growth by $50 \%$ in the LNCaP, C4 and C4-2 xenografts (22). Another study reported that IP injection of mifepristone at $12 \mathrm{mg} / \mathrm{kg} /$ day was associated with an approximately $33 \%$ prolongation of time to tumor progression compared to vehicle control, in castration-resistant CWR-22Rv1 cells (23). These studies suggested that mifepristone might have clinical benefits in improving the overall outcomes in $\mathrm{PCa}$ patients. Indeed, Taplin et al. have conducted a phase II trial using mifepristone for the treatment of patients with CRPC. Unfortunately, it was found that mifepristone had limited activity in these patients and caused a significant increase in testosterone, adrenal androgens, and DHT (18). These disappointing results suggested that mifepristone alone may not be effective in treating CRPC. Currently, clinical efficacy of the combination regimens of mifepristone with standard CRPC therapy is being tested, including an ongoing randomized, open-label phase I/II trial that investigates the safety and activity of the combination of mifepristone and enzalutamide in CRPC patients with rising PSA.

In the current study, we sought to evaluate the potential of mifepristone to enhance standard CRPC treatments using xenograft models of bone metastatic CRPC. Our results presented here show that mifepristone fails to demonstrate synergy in enhancing the efficacy of either docetaxel or enzalutamide in bone metastatic CRPC treatment. These data point to a more complex scenario than we expected regarding the mechanism of mifepristone action in PCa cells and its incorporation with standard of care for the treatment of CRPC.

PCa initially progresses in an androgen-dependent manner (26). In the setting of surgical or chemical castration, additional suppression of adrenal androgen synthesis can be achieved with glucocorticoid therapy. Glucocorticoids inhibit the release of corticotropin-releasing hormone from the hypothalamus and thereby suppress adrenal androgen steroidogenesis, which leads to the inhibition of androgendependent proliferation of PCa cells (27). Therefore, synthetic glucocorticoids (such as prednisone and dexamethasone) are frequently incorporated with standard treatment regimens for advanced $\mathrm{PCa}$, particularly in combination with chemotherapy (docetaxel and cabazitaxel) and/or radiotherapy $(28,29)$. Indeed, a number of retrospective studies and phase II trials have evaluated the effectiveness of glucocorticoids as single agents in CRPC patients and demonstrated certain degrees of serum PSA response (30). Due to their anti-inflammatory properties and ability to reduce toxic adverse effects of cytotoxic chemotherapy, the inclusion of glucocorticoids may help to improve the quality of life of patients, such as reducing bone pain and increasing appetite (31-33). More recently, glucocorticoids (such as prednisone) have been combined with abiraterone, a potent inhibitor of steroid $17 \alpha$-hydroxylase (CYP17A1) and androgen synthesis (34). The incorporation of glucocorticoids in the standard PCa treatment can partially counteract a reduction of circulating cortisol and a compensatory stimulation of adrenocorticotropic hormone in response to abiraterone treatment, thereby reducing side effects from CYP17A1 inhibition (35-37). Despite these clinical benefits of glucocorticoids, post-hoc analyses on several completed trials indicated that glucocorticoids have adverse effects on the overall outcomes (30). For example, the use of glucocorticoids is associated with inferior overall survival and higher rate of adverse effects in the AFFIRM study, a phase II trial of enzalutamide in CRPC patients (38). Similarly, in the COU-AA-301 phase III study that compared prednisone alone with its combination with abiraterone in chemoresistant CRPC, the prednisone arm had inferior overall 
survival on univariate analysis and exhibited worse baseline disease characteristics $(38,39)$. These unexpected negative effects suggest a complicated mechanism of action of glucocorticoids in PCa patients, particularly those at late stages and having a long-term use of glucocorticoids (30).

Accumulating evidence indicated that increased GR expression is a common feature of drug-resistant CRPC (23, 40). An elegant study from Arora et al. showed that GR can actually substitute for the AR to activate a similar but distinguishable set of target genes and is required for the maintenance of enzalutamide resistance. Furthermore, acute AR inhibition leads to GR upregulation due to relief of ARmediated feedback repression of GR expression, thereby conferring therapeutic resistance. Conversely, treatment with a GR antagonist, compound 15, effectively restored enzalutamide sensitivity (41). In a recent study, Kroon et al. found that GR is also significantly upregulated in docetaxeltreated primary $\mathrm{PCa}$ tissues when compared with chemonaïve tumors. Consistently, GR is increased in cultured PCa cell lines with acquired docetaxel resistance regardless of their AR status, and the treatment with GR antagonists (mifepristone and cyproterone acetate) reversed docetaxel resistance in these cells (42). Although it remains unclear whether GR upregulation in PCa cells significantly contributes to the observed adverse effects of glucocorticoids in clinical settings, these studies provided a rationale to exploit GR antagonism to re-sensitize CRPC cells to docetaxel and enzalutamide treatments. Given its promising pre-clinical activity against PCa growth and favorable safety profile, mifepristone was pursued as an ideal agent to antagonize GR signaling in CRPC and enhance the efficacy of docetaxel and/or enzalutamide. However, in contrast to previous observations in other models $(22-24,41,42)$, our results indicate that mifepristone has very limited activity against the skeletal growth of PCa cells, either used alone or in combination with docetaxel or enzalutamide. This controversy is further highlighted by other studies, where AR signaling was taken into account. In various pre-clinical models, it appears that GR exerts opposite effects on different populations of PCa cells (23); it inhibits growth of PCa cells with intact AR signaling $(43,44)$, and promotes growth of PCa cells lacking AR and expressing high levels of GR $(13,45,46)$. Therefore, it is plausible that GR antagonism with mifepristone in $\mathrm{C} 4-2$ cells, which express fully functional AR (47), may relieve the suppressive effects of GR on PCa cell proliferation, thereby attenuating the inhibitory efficacy of docetaxel or enzalutamide. In addition, it has been shown that mifepristone, when bound to AR mutant AR-E897A, exhibits comparable to or better agonist activity than that seen with AR agonists, DHT and R1881 (48). Mifepristone can also promote the interaction between $\mathrm{AR}$ and one of its coactivators, ARA70, in a dose-dependent manner, which may subsequently enhance AR transcriptional activity (49). The agonist activity of mifepristone on AR signaling may be largely context-dependent, that could further complicate the overall outcomes when mifepristone is used to treat CRPC, due to the high heterogeneity of CRPC.

Historically, cell line-derived xenograft models have been repeatedly shown to be valuable in triaging investigational antineoplastic agents (50). Taken together, our data could raise questions regarding the use of mifepristone for the treatments of patients with advanced PCa. It would be interesting to follow-up and review clinical results from the ongoing phase I/II trial NCT02012296.

\section{Conflict of Interest}

The Authors declare no conflict of interest.

\section{Acknowledgements}

This work was supported by National Cancer Institute grants 1R41CA206725-01A1, 1R41CA217491-01A1 and 1R41CA18649801A1, Georgia Cancer Center Startup Fund (D. Wu). We thank Dr. Rhea-Beth Markowitz at Georgia Cancer Center for editorial assistance.

\section{References}

1 Jacobs SC: Spread of prostatic cancer to bone. Urology 21(4): 337-344, 1983.

2 Jemal A, Siegel R, Ward E, Murray T, Xu J and Thun MJ: Cancer statistics, 2007. CA Cancer J Clin 57(1): 43-66, 2007.

3 Tu SM and Lin SH: Clinical aspects of bone metastases in prostate cancer. Cancer Treat Res 118: 23-46, 2004.

4 Petrylak DP, Tangen CM, Hussain MH, Lara PN Jr., Jones JA, Taplin ME, Burch PA, Berry D, Moinpour C, Kohli M, Benson MC, Small EJ, Raghavan D and Crawford ED: Docetaxel and estramustine compared with mitoxantrone and prednisone for advanced refractory prostate cancer. N Engl J Med 351(15): 1513-1520, 2004.

5 Tannock IF, de Wit R, Berry WR, Horti J, Pluzanska A, Chi KN, Oudard S, Theodore C, James ND, Turesson I, Rosenthal MA and Eisenberger MA: Docetaxel plus prednisone or mitoxantrone plus prednisone for advanced prostate cancer. N Engl J Med 351(15): 1502-1512, 2004.

6 McCain J: Drugs that offer a survival advantage for men with bone metastases resulting from castration-resistant prostate cancer: New and emerging treatment options. P T 39(2): 130$143,2014$.

7 van Dodewaard-de Jong JM, Verheul HM, Bloemendal HJ, de Klerk JM, Carducci MA and van den Eertwegh AJ: New treatment options for patients with metastatic prostate cancer: What is the optimal sequence? Clin Genitourin Cancer 13(4): 271-279, 2015.

8 Chen J, Wang J, Shao J, Gao Y, Xu J, Yu S, Liu Z and Jia L: The unique pharmacological characteristics of mifepristone (ru486): From terminating pregnancy to preventing cancer metastasis. Med Res Rev 34(5): 979-1000, 2014. 
9 Lanari C and Molinolo AA: Progesterone receptors - animal models and cell signalling in breast cancer. Diverse activation pathways for the progesterone receptor: Possible implications for breast biology and cancer. Breast Cancer Res 4(6): 240-243, 2002.

10 Sartor O and Figg WD: Mifepristone: Antineoplastic studies. Clin Obstet Gynecol 39(2): 498-505, 1996.

11 Romieu G, Maudelonde T, Ulmann A, Pujol H, Grenier J, Cavalie G, Khalaf S and Rochefort H: The antiprogestin ru486 in advanced breast cancer: Preliminary clinical trial. Bull Cancer 74(4): 455-461, 1987.

12 SoRelle R: Abortion pill gets fda approval. Circulation 102(15): E9030-9031, 2000.

13 Lin MF, Kawachi MH, Stallcup MR, Grunberg SM and Lin FF: Growth inhibition of androgen-insensitive human prostate carcinoma cells by a 19-norsteroid derivative agent, mifepristone. Prostate 26(4): 194-204, 1995.

14 Ji Y, Rankin C, Grunberg S, Sherrod AE, Ahmadi J, Townsend JJ, Feun LG, Fredericks RK, Russell CA, Kabbinavar FF, Stelzer KJ, Schott A and Verschraegen C: Double-blind phase iii randomized trial of the antiprogestin agent mifepristone in the treatment of unresectable meningioma: Swog s9005. J Clin Oncol 33(34): 4093-4098, 2015.

15 Esteve JL, Acosta R, Perez Y, Campos R, Hernandez AV and Texido CS: Treatment of uterine myoma with 5 or $10 \mathrm{mg}$ mifepristone daily during 6 months, post-treatment evolution over 12 months: Double-blind randomised clinical trial. Eur J Obstet Gynecol Reprod Biol 161(2): 202-208, 2012.

16 Ramondetta LM, Johnson AJ, Sun CC, Atkinson N, Smith JA, Jung MS, Broaddus R, Iyer RB and Burke T: Phase 2 trial of mifepristone (ru-486) in advanced or recurrent endometrioid adenocarcinoma or low-grade endometrial stromal sarcoma. Cancer 115(9): 1867-1874, 2009.

17 Rocereto TF, Saul HM, Aikins JA Jr. and Paulson J: Phase ii study of mifepristone (ru486) in refractory ovarian cancer. Gynecol Oncol 77(3): 429-432, 2000.

18 Taplin ME, Manola J, Oh WK, Kantoff PW, Bubley GJ, Smith M, Barb D, Mantzoros C, Gelmann EP and Balk SP: A phase ii study of mifepristone (ru-486) in castration-resistant prostate cancer, with a correlative assessment of androgen-related hormones. BJU Int 101(9): 1084-1089, 2008.

19 Seo SI, Gera L, Zhau HE, Qian WP, Iqbal S, Johnson NA, Zhang S, Zayzafoon M, Stewart J, Wang R, Chung LW and Wu D: Bkm1740, an acyl-tyrosine bisphosphonate amide derivative, inhibits the bone metastatic growth of human prostate cancer cells by inducing apoptosis. Clin Cancer Res 14(19): 6198-6206, 2008.

20 Mitsuo T, Rounds J, Prechek D, Wilmore DW and Jacobs DO: Glucocorticoid receptor antagonism by mifepristone alters phosphocreatine breakdown during sepsis. Arch Surg 131(11): 1179-1185, 1996.

21 Liu R, Shi P, Nie Z, Liang H, Zhou Z, Chen W, Chen H, Dong C, Yang R, Liu S and Chen C: Mifepristone suppresses basal triple-negative breast cancer stem cells by down-regulating klf5 expression. Theranostics 6(4): 533-544, 2016.

22 El Etreby MF, Liang Y, Johnson MH and Lewis RW: Antitumor activity of mifepristone in the human lncap, lncap-c4, and lncapc4-2 prostate cancer models in nude mice. Prostate 42(2): 99$106,2000$.

23 Isikbay M, Otto K, Kregel S, Kach J, Cai Y, Vander Griend DJ, Conzen SD and Szmulewitz RZ: Glucocorticoid receptor activity contributes to resistance to androgen-targeted therapy in prostate cancer. Horm Cancer 5(2): 72-89, 2014.

24 Ligr M, Li Y, Logan SK, Taneja S, Melamed J, Lepor H, Garabedian MJ and Lee P: Mifepristone inhibits grbeta coupled prostate cancer cell proliferation. J Urol 188(3): 981-988, 2012.

25 Zhang H, Lu JJ, Gao QZ and Zhang J: Induction of apoptosis by mifepristone in androgen-independent prostate cancer cell lines in vitro. Zhonghua Wai Ke Za Zhi 44(6): 382-385, 2006.

26 Colombel M, Olsson CA, Ng PY and Buttyan R: Hormoneregulated apoptosis results from reentry of differentiated prostate cells onto a defective cell cycle. Cancer Res 52(16): 4313-4319, 1992.

27 Geller J and Albert JD: Adrenal androgen blockade in relapsed prostate cancer. Eur J Cancer Clin Oncol 21(10): 1127-1131, 1985.

28 Dorff TB and Crawford ED: Management and challenges of corticosteroid therapy in men with metastatic castrate-resistant prostate cancer. Ann Oncol 24(1): 31-38, 2013.

29 Schwartz JR: Dexamethasone premedication for prophylaxis of taxane toxicities: Can the doses be reduced when paclitaxel or docetaxel are given weekly? J Oncol Pharm Pract 18(2): 250256, 2012.

30 Narayanan S, Srinivas S and Feldman D: Androgenglucocorticoid interactions in the era of novel prostate cancer therapy. Nat Rev Urol 13(1): 47-60, 2016.

31 Fakih M, Johnson CS and Trump DL: Glucocorticoids and treatment of prostate cancer: A preclinical and clinical review. Urology 60(4): 553-561, 2002.

32 Tannock I, Gospodarowicz M, Meakin W, Panzarella T, Stewart L and Rider W: Treatment of metastatic prostatic cancer with low-dose prednisone: Evaluation of pain and quality of life as pragmatic indices of response. J Clin Oncol 7(5): 590-597, 1989.

33 Nishimura K, Nonomura N, Yasunaga Y, Takaha N, Inoue H, Sugao H, Yamaguchi S, Ukimura O, Miki T and Okuyama A: Low doses of oral dexamethasone for hormone-refractory prostate carcinoma. Cancer 89(12): 2570-2576, 2000.

34 Ryan CJ, Smith MR, de Bono JS, Molina A, Logothetis CJ, de Souza P, Fizazi K, Mainwaring P, Piulats JM, Ng S, Carles J, Mulders PF, Basch E, Small EJ, Saad F, Schrijvers D, Van Poppel H, Mukherjee SD, Suttmann H, Gerritsen WR, Flaig TW, George DJ, Yu EY, Efstathiou E, Pantuck A, Winquist E, Higano CS, Taplin ME, Park Y, Kheoh T, Griffin T, Scher HI, Rathkopf $\mathrm{DE}$ and Investigators C-A-: Abiraterone in metastatic prostate cancer without previous chemotherapy. N Engl J Med 368(2): 138-148, 2013.

35 Attard G, Reid AH, A'Hern R, Parker C, Oommen NB, Folkerd E, Messiou C, Molife LR, Maier G, Thompson E, Olmos D, Sinha R, Lee G, Dowsett M, Kaye SB, Dearnaley D, Kheoh T, Molina A and de Bono JS: Selective inhibition of cyp17 with abiraterone acetate is highly active in the treatment of castrationresistant prostate cancer. J Clin Oncol 27(23): 3742-3748, 2009.

36 Ferraldeschi R, Sharifi N, Auchus RJ and Attard G: Molecular pathways: Inhibiting steroid biosynthesis in prostate cancer. Clin Cancer Res 19(13): 3353-3359, 2013.

37 Basch E, Autio K, Ryan CJ, Mulders P, Shore N, Kheoh T, Fizazi K, Logothetis CJ, Rathkopf D, Smith MR, Mainwaring PN, Hao Y, Griffin T, Li S, Meyers ML, Molina A and Cleeland C: Abiraterone acetate plus prednisone versus prednisone alone in chemotherapy-naive men with metastatic castration-resistant prostate cancer: Patient-reported outcome results of a randomised phase 3 trial. Lancet Oncol 14(12): 1193-1199, 2013. 
38 Scher HI, Fizazi K, Saad F, Taplin ME, Sternberg CN, Miller K, de Wit R, Mulders P, Chi KN, Shore ND, Armstrong AJ, Flaig TW, Flechon A, Mainwaring P, Fleming M, Hainsworth JD, Hirmand M, Selby B, Seely L and de Bono JS: Increased survival with enzalutamide in prostate cancer after chemotherapy. N Engl J Med 367(13): 1187-1197, 2012.

39 Montgomery B, Kheoh T, Molina A, Li J, Bellmunt J, Tran N, Loriot Y, Efstathiou E, Ryan CJ, Scher HI and de Bono JS: Impact of baseline corticosteroids on survival and steroid androgens in metastatic castration-resistant prostate cancer: Exploratory analysis from cou-aa-301. Eur Urol 67(5): 866-873, 2015.

40 Rane JK, Erb HH, Nappo G, Mann VM, Simms MS, Collins AT, Visakorpi T and Maitland NJ: Inhibition of the glucocorticoid receptor results in an enhanced mir-99a/100-mediated radiation response in stem-like cells from human prostate cancers. Oncotarget 7(32): 51965-51980, 2016.

41 Arora VK, Schenkein E, Murali R, Subudhi SK, Wongvipat J, Balbas MD, Shah N, Cai L, Efstathiou E, Logothetis C, Zheng D and Sawyers CL: Glucocorticoid receptor confers resistance to antiandrogens by bypassing androgen receptor blockade. Cell 155(6): 1309-1322, 2013.

42 Kroon J, Puhr M, Buijs JT, van der Horst G, Hemmer DM, Marijt KA, Hwang MS, Masood M, Grimm S, Storm G, Metselaar JM, Meijer OC, Culig Z and van der Pluijm G: Glucocorticoid receptor antagonism reverts docetaxel resistance in human prostate cancer. Endocr Relat Cancer 23(1): 35-45, 2016.

43 Nishimura K, Nonomura N, Satoh E, Harada Y, Nakayama M, Tokizane T, Fukui T, Ono Y, Inoue H, Shin M, Tsujimoto Y, Takayama H, Aozasa K and Okuyama A: Potential mechanism for the effects of dexamethasone on growth of androgenindependent prostate cancer. J Natl Cancer Inst 93(22): 17391746, 2001.
44 Smith RG, Syms AJ, Nag A, Lerner S and Norris JS: Mechanism of the glucocorticoid regulation of growth of the androgensensitive prostate-derived $\mathrm{r} 3327 \mathrm{~h}$-g8-a1 tumor cell line. J Biol Chem 260(23): 12454-12463, 1985.

45 Gabaglia CR, DeLaney A, Gee J, Halder R, Graham FL, Gauldie J, Sercarz EE and Braciak TA: Treatment combining ru486 and ad5il-12 vector attenuates the growth of experimentally formed prostate tumors and induces changes in the sentinel lymph nodes of mice. J Transl Med 8: 98, 2010.

46 Tieszen CR, Goyeneche AA, Brandhagen BN, Ortbahn CT and Telleria CM: Antiprogestin mifepristone inhibits the growth of cancer cells of reproductive and non-reproductive origin regardless of progesterone receptor expression. BMC Cancer 11: 207, 2011.

47 Wu HC, Hsieh JT, Gleave ME, Brown NM, Pathak S and Chung LW: Derivation of androgen-independent human lncap prostatic cancer cell sublines: Role of bone stromal cells. Int J Cancer 57(3): 406-412, 1994.

48 Klokk TI, Kurys P, Elbi C, Nagaich AK, Hendarwanto A, Slagsvold T, Chang CY, Hager GL and Saatcioglu F: Ligandspecific dynamics of the androgen receptor at its response element in living cells. Mol Cell Biol 27(5): 1823-1843, 2007.

49 Miyamoto H, Yeh S, Wilding G and Chang C: Promotion of agonist activity of antiandrogens by the androgen receptor coactivator, ara70, in human prostate cancer du145 cells. Proc Natl Acad Sci USA 95(13): 7379-7384, 1998.

50 Day CP, Merlino G and Van Dyke T: Preclinical mouse cancer models: A maze of opportunities and challenges. Cell 163(1): 39-53, 2015.

Received September 8, 2017

Revised September 26, 2017

Accepted September 28, 2017 